\title{
En La Rosa de los vientos. Una mirada marxista de la Revolución Mexicana.
}

\author{
In the Rose of the winds. A Marxist look at the Mexican Revolution. \\ Ángel Chávez Mancilla \\ Escuela Nacional de Antropología e Historia (MÉXICO) \\ CE: angelch.mancilla@gmail.com ID ORCID: 0000-0002-0263-1493
}

DOI: $10.32870 /$ sincronia.axxiii.n76.25b19

CC) $\mathrm{BY} \cdot \mathrm{NC}$

Esta obra está bajo una Licencia Creative Commons Atribución-NoComercial 4.0 Internacional

Recibido: $25 / 03 / 2019$

Revisado: 20/05/2019

Aprobado: 20/06/2019

\section{RESUMEN}

José Mancisidor escribió sus novelas apoyándose en la concepción marxista de la historia, lo que le permitió pensar y describir la Revolución mexicana en forma bastante distinta a otros novelistas. Consciente de este fenómeno reconoció que su novela En la rosa de los vientos fue ideada desde el marxismo como crítica y contraparte de Los de abajo de Azuela. Atendiendo a esta confidencia de Mancisidor, en el presente trabajo se exploran dos de los elementos de su ideología presentes en su mencionada novela: la lucha de clases y el método del realismo socialista. Para esto se analizarán la concepción general que tenía de la Revolución mexicana, las características que le asigna a sus personajes principales -con las cuales los hace representes de una determinada clase social-, y las del realismo socialista a que atiende.

Palabras clave: José Mancisidor; Novela de la Revolución mexicana; marxismo; realismo socialista; lucha de clases. 


\begin{abstract}
:
José Mancisidor wrote his novels based on the Marxist conception of history, which allowed him to think and describe the Mexican Revolution quite differently from other novelists. Aware of this phenomenon, he acknowledged that his novel In the Rose of the winds was conceived from the Marxist as a criticism and counterpart of Azuela's The Underdogs. Attending to this confidence of Mancisidor, in the present work will be evident two of the elements of his ideology that are presented in his aforementioned novel: the class struggle and the method of socialist realism. For this, the general conception that he had of the Mexican Revolution, the characteristics he assigns to his main characters -with which he makes them representatives of a certain social class- and the characteristics of the socialist realism that he serves, will be analyzed.
\end{abstract}

Keywords: José Mancisidor. Novel of the Mexican Revolution. Marxism. Socialist realism. Class struggle.

\title{
Introducción
}

La obra literaria de José Mancisidor cuenta con poca difusión, esto lo atestiguan las pocas reediciones con que cuenta; de sus ocho novelas, sólo dos han tenido la fortuna de contar con más de dos ediciones: Ciudad roja y En la rosa de los vientos. De igual forma, ha sido objeto de escasos estudios particulares (León, 1964; Gutiérrez, 1983), y en las historias generales de la literatura mexicana, se le menciona apenas de paso (Hernández, 1960, pp. 180-182; Martínez y Domínguez, 1995, p. 95, 100-101; Martínez, 1949, p. 50-52). Además cuenta con poca difusión

Probablemente el trasfondo ideológico marxista desde el cuál escribió José Mancisidor, influyó en que su obra literaria fuera poco difundida y no pasara a formar parte del canon de la literatura avalada y divulgada por el Estado mexicano y sus instituciones. Por la propagación de la ideología socialista a partir de la Revolución Rusa y la participación de la URSS en el combate al fascismo, los momentos de mayor difusión de las novelas de Mancisidor fueron las décadas de 1940 
y 1950, cuando su obra llegó a ser traducida y dada a conocer en diversos idiomas de países pertenecientes del bloque socialista. (Hernández, 1960, p. 181).

Debido a la amplitud de temas que tocó Mancisidor, el conjunto de su obra puede adscribirse a los géneros de la novela proletaria (Dessau, 1996, pp. 302-305; Negrín, 1992) y la novela de la Revolución Mexicana (Martínez \& Domínguez, 1995, p. 95; Dessau, 1996, pp. 16-17; Castro, 1965, Torres, 2015). Principalmente se le ha destacado como autor del primer género, dejando su participación en la novela de la Revolución mexicana a la sombra de autores más conocidos como Mariano Azuela y Martín Luis Guzmán, pero tal fenómeno es comprensible por múltiples factores, el principal es que la impronta marxista de Mancisidor aleja su obra de la misión que el gobierno surgido de la Revolución mexicana asignaba a la Novela de la Revolución mexicana: de auto representación y publicidad efectiva (Higashi \& Torres, 2010, p. 386). A esto se suma el que Mancisidor presenta una visión opuesta a la de Azuela respeto de la Revolución (Olea, 2012, pp. 2122); y algunos defectos, por ejemplo el que Monsiváis le atribuye: "Mancisidor, narrador más bien deficiente" (1990, p.6), y la acusación de que atribuye a los personajes ideas y conceptos con los que no podían contar (Mata, 2010). Pero la riqueza de su obra, independientemente de las críticas y el género al que se adscriba, reside en la particular visión que expresa de la realidad social que retrata. Ante tal panorama, el objetivo del presente trabajo es analizar y destacar las virtudes y peculiaridades que presenta la que podría ser su obra más claramente inserta en el género de la novela de la Revolución mexicana: En la rosa de los vientos. ${ }^{1}$

En el presente análisis se profundizará y se discutirá la información y algunas de las ideas más relevantes que hasta el momento se han producido sobre el tema elegido. Como eje central de estudio se tomará la ideología política de Mancisidor, y por tanto partiremos de que la concepción de la Revolución mexicana que presenta En la rosa de los vientos, es distinta a la de otros novelistas, principalmente debido a que fue concebida y estaba impregnada de la ideología marxista. (Berrios, 1978, pp. 44-65; Dessau, 1996, p. 304). Por tanto, desde este enfoque metodológico, en el presente

\footnotetext{
${ }^{1}$ Para el presente trabajo se utilizó la edición incluida en el tomo III de las Obras completas de José Mancisidor publicado en 1979. El material consultado no tiene diferencias con la primera edición que da de 1940.
} 
estudio se destacarán los elementos que hacen de En la rosa de los vientos una visión marxista de la Revolución mexicana y una novela partícipe del realismo socialista: la manera en que las características y aspiraciones de los personajes principales representan los intereses de distintas clases sociales y posiciones políticas; en la forma en que se deifica a la clase obrera como vanguardia de la transformación revolucionaria, y, por último, la exposición de la Revolución mexicana, como una revolución democrático burguesa (Mancisidor, 1977, p. 313) en la que se cumplieron a medio camino las demandas de obreros y campesinos.

El marxismo dotó a Mancisidor de una forma particular de apreciar el desarrollo históricosocial, y armado de las ideas del marxismo ortodoxo concebía como fenómeno central del cambio histórico a la lucha de clases y a la clase obrera como el sujeto principal llamado a emancipar y librar de la explotación al resto de los explotados, siempre y cuando adquiera conciencia de clase. Esto lo constata de forma explícita su producción historiográfica (Sánchez, 1994, pp. 31-32; Lacroix \& Portilla, 1978, p. 62), principalmente la Historia de la Revolución Mexicana (1976) y la Síntesis histórica del movimiento social en México (1940). Así pues, cuando Mancisidor interpreta la Revolución mexicana, ve los estragos como males necesarios; y al describir a los personajes, en realidad refiere la situación e intereses de distintas clases sociales.

No obstante, hay que especificar que, si bien Mancisidor retoma los elementos generales de la teoría Marxista, como señala Sánchez (1940), eran pocos los textos de Marx y Engels que circulaban en México (1994, p. 31), y su concepción estaba vinculada al marxismo soviético (Matute, 2005, p. 32). Por tanto, aunque por los rasgos generales es una visión marxista, dista de otras interpretaciones vinculadas al marxismo, como las que hicieron décadas después Arnaldo Córdova o Katz (Matute, 2005, p. 55-70). También repercute en su concepción de la historia, la política de la Internacional Comunista que consideraba a México como un país dependiente en el ámbito económico y por consiguiente, situaba que, durante la Revolución mexicana y las décadas siguientes, el principal conflicto era entre "la burguesía nacional fortalecida en la Reforma y el capitalismo extranjero". (Sánchez, 1994, p. 30). 
El marxismo de corte soviético, al que se afilió Mancisidor, concibió que la producción intelectual también debía responder a la lucha de clases; es por ello que su novela también revela al marxismo, dado que fue pensada como instrumento de confrontación ideológica contra el realismo crítico subyacente en obras como Los de abajo de Mariano Azuela. Esto coloca a Mancisidor como representante del realismo socialista surgido en la URSS, y como expresión de las posiciones revolucionarias de la clase obrera. (Mancisidor, 1980a, pp. 823-850).

De esta forma, se hace un llamado a revalorar la obra de Mancisidor, a fin de que pueda dejar de ser visto como un autor secundario o menor, y pase a observar como exponente de una visión política-ideológica que en su momento se constituyó de manera subalterna.

\section{Una mirada general a la Revolución Mexicana}

El contexto en que Mancisidor escribió En la roda de los vientos estuvo marcado por el nuevo brío que la política del gobierno de Lázaro Cárdenas le a la Revolución mexicana, de la cual se consideraba que su gobierno era la continuación. Su obra resultó premiada y posteriormente publicada por Edición y Distribución Iberoamericana de publicaciones (E.D.I.A.P.S.A.) en 1941. Al igual que otras novelas de la Revolución mexicana, En la rosa de los vientos es producto de las vivencias que el autor experimentó en la Revolución. A lo largo de los XXXI capítulos que conforman dicho libro, Mancisidor narra sus andanzas antes, durante y después del conflicto armado, así como el ir y venir de los campesinos y obreros, rememorando y añadiendo de forma consciente elementos ficcionales a la realidad histórica representada, cuando describe a los personajes y sus acciones.

Es posible que sus vivencias plasmadas de forma novelesca sean en realidad pretexto para poder presentar una nueva visión de los acontecimientos políticos, sociales y militares que padeció México a inicios del siglo XX, pues, como el mismo Mancisidor revela, la trama y los personajes fueron pensados con el interés de exponer una visión alterna a la que difundió Mariano Azuela con sus obras, principalmente en Los de abajo (Mancisidor, 1980b, pp. 769-775). Sumado a esto, la 
forma en que muestra los acontecimientos de la Revolución, hace parecer su vida como secundaria y supeditada, en última instancia, a los sucesos políticos que se vivían en el país.

Los acontecimientos históricos que narra Mancisidor, corresponden, en la realidad histórica, a una temporalidad bastante extensa: aborda desde los años previos al estallido revolucionario de 1910, y llegan hasta poco después del final de la Revolución que, según él reconoce, se concreta hacia 1917 con la consolidación del gobierno de Carranza y la expedición de la constitución. Desde este enfoque, En la rosa de los vientos pasa a ser, probablemente, la novela de la revolución mexicana que aborda el periodo temporal más amplio, permitiendo al autor narrar distintas etapas de la revolución en paralelo con el avance de su edad.

En los primeros once capítulos, Mancisidor empieza por narrar su vida hasta los dieciséis años y la situación de México que se vivía previa al estallido de la Revolución. En el capítulo XII, narra el acontecimiento armado, en el XIV, su ingreso a las filas constitucionalistas (1979, pp. 124125), y, hasta el XIX, la lucha contra Victoriano Huerta. En el XX, narra el paso a la lucha de facciones al decir:

Después de éste combate el enemigo quedó vencido definitivamente. El camino está limpio para llegar a la Capital. Nada nos detiene. Se acabaron los obstáculos... No obstante, no hay quien crea en el final de la contienda. Todos sabemos que una nueva lucha se prepara." (Mancisidor, 1979, pp. 124-125).

En el mismo apartado (apartado), el autor cuestiona sutilmente la idea de que la Revolución triunfara con la derrota de Huerta, como se puede apreciar en el siguiente pasaje:

El jefe nos invita a cenar. Alrededor de una mesa a la que nos sentamos todos los oficiales del regimiento, la alegría cunde. Por las ventanillas del carro la luna cuela su fulgor. Antes de levantarnos, el jefe brinda por el triunfo de la Revolución. Todos aplauden y todos gritan. Pero, ¿̇es acaso que ha triunfado la Revolución? (Mancisidor, 1979, p. 171).

Aunque el autor no hace referencia la convención de Aguascalientes, es posible considerar, a partir de ciertos indicios, que acontece entre los capítulos XX y XXI. La división del ejército 
constitucionalista, con la escisión de las tropas de Francisco Villa, y el resultado de la convención de Aguascalientes, se presentará a partir del capítulo XXII, en que se describe la lucha entre la facción constitucionalista y la de Villa-Zapata, como un caos que impide ver con claridad, donde y ante los ojos de la tropa se presenta como una amalgama de confrontaciones militares sin sentido. El sinsentido surge debido a que, a quienes confronta la tropa de Mancisidor, son al campesino y al obrero que sigue teniendo los mismos intereses que el obrero y campesino del ejército constitucionalista. No obstante, los obreros y campesinos de ambos bandos carecen de la solución de sus demandas.

Este pasaje de la historia de la Revolución, Mancisidor lo narra, al contrario de lo que ha hecho previamente, anteponiendo el dominio del caos a la concepción que le había permitido explicar cada paso previo de la lucha armada:

De pronto nadie sabe contra quien combate. Combatimos a todas horas, por la noche y por el día con un enemigo que se reproduce. Brota de todos los resquicios de la tierra como si la tierra pusiera en pie a todos los muertos que en su seno mantenía. Es un caos que nadie entiende." (1979, p. 183).

También es posible afirmar que en el capítulo XXII Mancisidor presenta la lucha de facciones posterior a la Convención de Aguascalientes efectuada en 1914. El otro acontecimiento relevante, con que se afirma la lucha de Carranza contra Villa y Zapata, es la creación de los Batallones Rojos, producto del pacto entre la Casa del Obrero Mundial y el gobierno de Carranza en febrero de 1915, fecha para la que contaría ya con 21 años. Los batallones rojos son la única organización y fuerza militar a la que hace referencia explícita: "Con nosotros marchaban los primeros Batallones Rojos. Obreros textiles, mineros y ferroviarios" (1979, p.183).

Entre el capítulo XXII y el XXVIII, los acontecimientos que narra, se refieren a la lucha contra las fuerzas de Villa. En particular, es probable que los capítulos XXVI y XXVII retraten el contexto de la batalla de Celaya y el triunfo de Álvaro Obregón sobre las fuerzas villistas. Esto es posible, dado que hace referencia a que el enemigo, luego de ser enfrentado y derrotado en múltiples encuentros 
militares, "se retira poco a poco. Hostilizándonos sin cesar. Se retira kilómetro a kilómetro sin recoger sus muertos y abandonando a sus heridos" (1978, p. 239). En otra parte menciona: "Día y noche machacamos las líneas contrarias. En un incesante martillear de olas humanas que se deshacen en las rompientes de fisiles y bayonetas enemigas" (1979, p. 241).

Entre los capítulos XXVIII y XXIX describe la situación política surgida del triunfo del ejército de Carranza y Obregón ante las fuerzas de Villa, acontecimiento que parecía dibujar el camino para la paz oficial. De esta forma surge en la trama una nueva problemática, retrata el licenciamiento de los batallones rojos y la represión violenta que Carranza desató contra el movimiento obrero, cuyo ejemplo más significativo fue la represión de la huelga general de julio de 1916 en la Ciudad de México.

La forma en que retrata la represión gubernamental del movimiento obrero es simbólica. Si bien no describe la represión de la huelga general de 1916, sí captura la situación general. Él, como miembro del ejército, recibe la orden de acudir a reprimir una huelga en las calles de la Ciudad de México; entre los obreros que protestan se encuentra Efrén, su amigo de la escuela que como representante de la clase obrera acusa de traidor a Mancisidor: “- ¿Por qué no disparas?- Me gritó descompuesto. ¿por qué? ¿Traidor? - La frase me cruzó como un latigazo y sentí que la sangre afluía a él." (1979, pp. 279-280).

Es posible que en este pasaje acuse de traición al gobierno de Carranza, aunque en su obra historiográfica lo presente como el paladín de la Revolución. Lo cierto es que tomará una decisión por la cual el gobierno terminará por licenciarlo del ejército:

El no haber disparado sobre los obreros es mi delito. El jurado que me juzgó me ha condenado a ser borrado de los cuadros del ejército. $Y$ de pronto me he encontrado una vez más frente a la vida, perdido en la rosa de los vientos. (1979, p. 281).

Para la concepción de, el fin de la lucha armada era una primera parte de la lucha que los obreros, y sobre todo los campesinos, habían emprendido al enrolarse en la Revolución. Así, pues, en el antepenúltimo capítulo el narrador menciona: "La luchar armada había terminado. La Revolución 
contaba con un código agrario y toda una legislación del trabajo" (1979, p. 266). Es decir, para la Revolución termina con la proclamación de la constitución de 1917 en que los obreros y campesinos ven plasmadas sus demandas en la Carta Magna.

En el final de la novela, el personaje protagonista, se retira a cultivar la tierra entregada por el reparto agrario. Pero esto no quiere decir que considerara que había llegado el final de la lucha de los obreros y campesinos, en su concepción política, la lucha de éstos continuó siendo necesaria para que se cumplirán sus peticiones, ya que Carranza había convertido las demandas de estos sectores en banderas de lucha corriendo el peligro, como de hecho ocurrió, de que se demorara y evitara el cumplimiento de la constitución. ${ }^{2}$ Tal idea la describe de la siguiente forma:

Pero la lucha toma nuevo rumbo, otros derroteros. Ya no era el combate feroz del hombre contra el hombre, rayano en la bestialidad, entre chocar de sables y cargas de caballería. Tampoco hablaban ya las voces roncas de la artillería, ni ladraban con sus agudos y persistentes ladridos los fusiles y las ametralladoras. Ahora se trataba de una lucha sorda, callada y escondida pero tan feroz como la anterior, en que los hombres dirimían esta vieja cuestión de la tierra. (1979, p. 253).

La breve reseña que se ha presentado puede servir también de guía para la lectura de la novela, pues el autor no utiliza en ningún momento los nombres de los caudillos de la Revolución, tampoco hace referencia a documentos o planes, menos aún, refiere fechas importantes, lo que hace complicado la identificación de los procesos y etapas de la Revolución que aborda en su novela.

\section{El realismo crítico frente al realismo socialista}

La Novela de la Revolución Mexicana ha sido identificada como una expresión del realismo crítico (Dessau, 1996, p. 16-17; Carballo, 1964, pp. 7-32), no obstante, existen múltiples rasgos que diferencian al conjunto de los autores que se agrupan bajo el nombre de Novela de la Revolución mexicana, cuestión que ya ha sido trabajada por autores como Antonio Castro Leal (1960),

${ }^{2}$ La idea de que la lucha de los obreros y campesinos no había terminado con la promulgación de la Constitución de 1917 se expresa de forma explícita en su texto Síntesis histórica del movimiento social en México (1940, pp. 319-331). 
Adalberto Dessau (1996) y Max Aub (1985), entre otros. Sin embargo, la visión de Sara Sefchovich (1987, p. 71-101) permite repensar la visión general que se tiene de la novela de la Revolución Mexicana. Sefchovich destaca los elementos generales, que según Castro Leal, el más consagrado de los estudiosos de este género, son los más comunes en la narrativa de la Revolución mexicana, recuperando los siguientes: choques sangrientos de facciones enemigas, ejércitos improvisados, ataques a las ciudades y atropellos a la población, asaltos y saqueos, angustia de la población, héroes, etc. (1987, p. 88). En síntesis:

...hombres generosos que querían salvar a los pobres y que al enriquecerse olvidan sus convicciones: todo un pueblo que se levanta desde la servidumbre hasta el libertinaje, desde la ilegalidad hasta la Constitución de 1917, reivindicaciones que se externan en venganzas, masas que forjan en la lucha los principios que las guían, movimiento unánime y violento que -dueño ya de la situación- retarda el triunfo y la organización final mientras se despedazan los caudillos rivales impulsados por ambición de poder. (Leal, 1965, p. 18).

Estos elementos hacen parecer a la Revolución como un proceso caótico en que las aspiraciones de cambio se ahogan y los participantes caen en la degeneración moral y mueren por los intereses personales de caudillos corrompidos o por disputas que nada tenían que ver con sus aspiraciones de transformar la situación social. ${ }^{3}$ Esta es la concepción que subyace a la obra Los de abajo de Azuela, como diría Ruffinelli “cuando Azuela habla sobre las masas exhibe que se ha desengañado de ellas y narra su oscura barbarie". (1982, p. 67). Por comprobación basta pensar en el personaje central de Los de abajo, los motivos del ingreso a la Revolución y la trayectoria y final de Demetrio Macías, que rompen con cualquier idealización que se pudiera tener de los miles de campesinos que participaron en la Revolución, haciendo dudar de que la demanda de tierra fuera el motor de la Revolución.

${ }^{3}$ Con base en los rasgos de carácter negativo (héroes degradados que ejecutan acciones inmorales 0 salvajes) que algunos novelistas retrata la Revolución Mexicana, Ruiz Abreu busca reinterpretar la Novela de la Revolución mexicana como expresión de trasgresión de la vida normal y por tanto aproximarla a lo que implica una situación festiva en que lo popular irrumpe (2010). 
Mancisidor se opuso a esta visión de la Revolución mexicana, declaró: “No: la Revolución no había sido sólo hurto, rapiña y anarquía. Fue a veces, esto; pero fue, así mismo algo más" (1980b, p. 773) y criticó la obra de Azuela diciendo:

A la necesidad de poner de relieve que siendo Los de Abajo una novela realista, lo era solamente a medias, pues no describía sino una parte de la realidad. Porque la Revolución fue un hecho de raíces profundas que pudo triunfar, como el héroe del mito legendario, sólo porque recibió del pueblo mexicano su aliento y su sangre. (1980b, p. 775).

Al igual que Mancisidor, Sefchovich se opuso a la visión crítica y desilusionada de la Revolución, y en la búsqueda de una explicación para el surgimiento de esta visión encarnada por Azuela, afirmó:

[...] no tiene razón Castro Leal cuando afirma que esta novelística se escribió para el pueblo, para entender sus luchas, para apoyarlo. No. Se hizo porque los autores querían explicarse a sí mismos los hechos en que participaban, algunos con entusiasmo, otros con oposición. (1987, p. 97).

Esta observación es relevante en medida que lleva a considerar que detrás de cada novela de la Revolución mexicana hay una concepción particular del proceso histórico, una explicación que se construye desde los intereses del autor, desde sus simpatías y aversiones.

Intentando explicar el surgimiento de la visión crítica y desilusionada de la Revolución, Sefchovich consideró que:

La respuesta se puede buscar en sus autores: las novelas las escribió una clase media que creyó en la Revolución y en 'la esperanza de una vida más justa, como decía José Rubén Romero, pero que se asustó ante la violencia y la barbarie, el desorden, y la facilidad de la muerte que no cabían en sus valores. La crítica fue pequeñoburguesa y liberal, hecha desde el individualismo, el amor por la propiedad privada y el miedo a las masas. (1987, p. 96-97).

Esta crítica está basada en la concepción marxista que considera que en una obra literaria siempre se expresa la concepción de clase del autor, cuestión polémica pero instituida como elemento del 
análisis literario en la Unión Soviética (Lifshitz, 1985; Zhdanov, 1968) llevó a Sefchovich a criticar la obra de Azuela mencionando que no había logrado entender o encontrar sentido a las escenas de violencia que presenció e incluso le censura su final actuación: "se encerró en su consultorio de la colonia Santa María la Ribera a escribir novelas amargadas." (1987, p. 97).

Partiendo de la explicación de Sefchovich, una concepción distinta de la Revolución mexicana puede ser expresada por un novelista que no perteneciera a las clases medias, sino a los estratos de trabajadores empobrecidos, pues para ellos serían personajes provenientes de éstos los que podrían ostentar una visión de la historia desde el marxismo, considerado como la ideología de la clase obrera. A tales características responde Mancisidor, hijo de una familia obrera (Mancisidor, 1979, pp. 12-15; Berrios, 1978, pp. 17-21) y que cuenta con la ventaja de estar adscrito ideológicamente al marxismo. Por esto extraña que Sefchovich no se detenga más en Mancisidor.

Es posible afirmar que justamente la concepción marxista de Mancisidor fue la base para concebir En la rosa de los vientos, pues como él mismo declara, ante el realismo crítico de Azuela que presentaba a medias la realidad "me prometí escribir una novela que diera una imagen más completa de la Revolución. Así ideé En la rosa de los vientos y así tracé su bosquejo." (1980b, p. 773). Por tanto, la novela de Mancisidor es una crítica al realismo de Azuela y bien podría ser que Mancisidor aplicara a Azuela la misma visión que tenía de los escritores realistas de Europa: "Toda la literatura realista de Occidente naufraga en un mar de temores, de incertidumbres" (1980a, p. 830), y ante el caos que ve Azuela en la Revolución bien podría anteponerse la consideración de que: "Más si la literatura realista ha sido firme en sus aspectos humanistas y en el amor al hombre, no logró rebasar los límites del humanismo psicológico, ni el amor, la piedad y la pena simplemente por el hombre abstracto." (Mancisidor, 1980a , p. 835).

Estas críticas están construidas desde la concepción político-ideológica del marxismo y la concepción del realismo socialista ${ }^{4}$ que difundió y antepuso al realismo a secas o realismo crítico.

${ }^{4}$ La concepción del realismo socialista fue consolidada en 1934 por Andrei Zhdanov (2019) en el Primer Congreso de Escritores Soviéticos, donde declaró: "La veracidad y la exactitud histórica de la imagen artística deben vincularse con la tarea de la transformación ideológica, de la educación de los trabajadores en el espíritu del socialismo. Este método en la ficción y la crítica literaria es lo que llamamos el método del 
(1980a , pp.823-852) Esto no es cosa extraña considerando que Mancisidor estaba influenciado por los debates habidos en la URSS sobre el realismo y el realismo socialista. Si bien, la Revolución mexicana no fue una revolución socialista, y el autor bien lo sabía, el realismo socialista no se limitaba para él a narrar la revolución Socialista, sino que tenía como determinantes otras características. Por ejemplo, para él, un elemento esencial del realismo socialista era que:

En contraposición al realismo crítico, el realismo socialista no insiste en ideales abstractos, sino en el hombre real, tomado de la realidad real sobre la tierra real. Este hombre es el luchador activo, constructor de una nueva vida, que actúa en lo más profundo de los hechos, y que trae consigo las cualidades y las tendencias de su época. (1980a, pp. 864-865).

Más clara es la sentencia que atribuye a Stalin, según la cual:

el escritor, o para mejor decir el creador de imágenes literarias no debe circunscribir su misión a la de un intrascendente relator de la verdad. Porque la más elevada tarea que a él le está encomendada es la de construir el alma de los explotados, haciéndoles descubrir la causa de su miseria material y espiritual, y enseñándoles a penetrar en la raíz histórica que las engendra. (1980a, p. 900).

Para este autor, las historias de personajes como Demetrio Macías en poco contribuían a esto, no indicaban o impulsaban el proceso revolucionario. Tampoco bastaba con el relato de las condiciones de vida de los trabajadores y campesinos, con retratar sus padecimientos, la realidad sangrienta y brutal de la lucha armada. Si la novela no indicaba quiénes eran los enemigos de los trabajadores, si no contribuía a clarificarles el camino de la organización y la lucha revolucionaria, debía ser sometida a crítica. Los de abajo de Azuela cumple las condiciones para ser criticada por Mancisidor como realismo crítico insuficiente para las labores de educación y orientación de los trabajadores.

Contrario a Los de abajo, En la rosa de los vientos busca representar a las clases sociales que participaron en la Revolución mexicana, exponer sus demandas y aspiraciones. En las reflexiones de lucha de clases no existe ni puede haber literatura que no sea de clase, tendenciosa o apolítica." 
los personajes se presentan las explicaciones de la realidad, los avances que hay en la obtención de sus demandas, los aprendizajes que les quedan del proceso revolucionario y la idea de que, aun cuando la mayoría de los participantes no son conscientes de los motivos profundos y la lógica a que responde el proceso de la Revolución, se avanza en el camino correcto por la claridad de algunos cuantos como León Cardel y por los aprendizajes que logran otros como El canteado. Así, a través de En la rosa de los vientos, diría el mismo Mancisidor "refleja los esfuerzos de los diversos grupos participantes en la Revolución combatiendo, cada uno de ellos, por los objetivos propios de las clases sociales que representan" (1980a, p. 885) y en este sentido es posible reconocer que se inserte en el realismo socialista.

\section{De obreros y campesinos. Los personajes de Mancisidor}

Además de los elementos del realismo socialista, la concepción marxista de la historia de Mancisidor se puede apreciar en las cualidades y acciones de sus personajes. El devenir del conjunto de sus personajes representa el devenir de las clases sociales que participaron de la Revolución, siempre con la idea marxista de que la clase obrera está llamada a ser el sujeto histórico del cambio social, el campesino pobre a ser su aliado y ambos encabezados por intelectuales orgánicos. Por tanto, el primer elemento que destaca de su concepción por contraste con la obra de Azuela es que aparece el obrero, como clase y como individuo, como personaje que es parte central del relato. De esta forma la obra de Mancisidor rompe con el imaginario colectivo que presenta al campesino que encabezado por los caudillos militares es el principal sujeto colectivo del proceso revolucionario.

Además de esto, los personajes de la novela en cuestión, fueron pensados meticulosamente por Mancisidor para oponer su visión marxista de la Revolución a la visión crítica y pesimista de Azuela. Esto implicaba que se dejaran claras las aspiraciones de los participantes, los trabajadores del campo y la ciudad, para demostrar que las muertes y excesos tenían una finalidad, y había quienes, en medio del aparente caos, tenían claridad para direccionar a los participantes menos consientes o poco claros. Al respecto declara: 
Frente a Demetrio Macías yo levantaría mi Canteado y contra el Curro yo crearía mi León Cardel, personajes de la realidad revolucionaria que yo viviera desde muy joven y que no me costaría trabajo identificar con los personajes de la vida real. $\mathrm{Y}$ ante aquella corte de Demetrio Macías, tan negativa, yo pondría a mis viejos compañeros de escuela como el Chino, el Negro y Efrén, y al Tejón, Rayado, al maestro Mercier y al Rata, que hombres que si no siempre puros en sus acciones, sí lo eran en sus sueños, en sus ilusiones y en sus esperanzas. (Mancisidor, 1980b, p. 773).

Los personajes que enuncia Mancisidor son algo más que una respuesta a Azuela, en ellos se puede apreciar la filiación marxista del autor, en conjunto representan una visión optimista de la Revolución, personifican también a los individuos conscientes de las metas y objetivos de la misma y las clases sociales que participaron; los diálogos y reflexiones que les asigna expresan los deseos y preocupaciones de los miles de obreros y campesinos que enfrentaron las desventuras y triunfos que la Revolución. Pasemos a analizar los principales personajes y la posible significación que desde el marxismo les asignó Mancisidor.

\section{a) El Canteado o la lucha por la tierra}

El Canteado es el representante de los campesinos, su principal aspiración es la tierra, y a diferencia de Demetrio Macías, él se sumó a la Revolución consciente de que era la única forma de cumplir su aspiración, la cual no abandonó sino hasta que se cumplió, hecho que ocurre en el último capítulo de la novela. Algunos diálogos reflexivos que Mancisidor le asigna a este personaje dan idea de esto:

- ¿Qué es nuestra lucha?, -nos había sugerido un día-. ¿El afán acaso de cambiar de amo? Lanzó una sonora interjección y dijo:

- Para nosotros, los hombres del campo, es algo más que eso. ¿Cómo podíamos conformarnos con tan poco? Nosotros queremos la tierra. Peleamos por la tierra. Somos sus hijos directos. Nos agarra a ella el cordón umbilical que en su seno nace. ¿Qué valemos nosotros si carecemos de un pedazo de tierra? Por eso la abonamos con nuestros huesos y 
nuestra carne. No hay un rincón de la tierra que no esté empapado con nuestro infinito sufrimiento. (1979, p. 153).

En este fragmento, Mancisidor retrata que el Canteado tenía claro porque luchaba, su demanda no era la misma que la de Madero, cambiar de gobierno, sino una distinta: la tierra para los campesinos que la trabajan. Además presenta la muerte de los campesinos, no como algo absurdo e incomprensible como lo ve Azuela ${ }^{5}$, sino como un mal necesario, como el costo de obtener la tierra. Aquí la obra Mancisidor presenta la concepción Marxista de la realidad, movida por la lucha entre las clases sociales, la necesidad de la lucha violenta como única salida a las contradicciones o conflictos de intereses contrarios. Pero todo lo que se encuentra detrás del citado argumento del Canteado no es sólo, como dijimos antes, la voz del individuo, sino la voz de una colectividad que habla por medio de él en la medida que:

Para el Canteado el tema era inagotable. Y sus soldados, campesinos todos del Norte, lo escuchaban sugestionados. Para ellos la razón de lucha del Canteado era su propia razón. La tierra los había parido. Hijos y padres, nietos y abuelos habían vivido metidos en la tierra."(1979, p. 154).

Como partidario de la visión marxista, Mancisidor no enaltece al campesino como el principal sujeto de la Revolución, aún de la mexicana; por lo que el Canteado, principal represéntate de los campesinos sumados a la Revolución, aunque tiene clara su idea de los motivos de la Revolución, no son éstos los más profundos. Incluso Mancisidor acusará a este personaje de estrechez de miras al contraponerlo en dos ocasiones al intelectual León Cardel (1979, pp. 157-162, 183-187) y de forma constante con el Rata. Uno de los pasajes más representativos es el siguiente:

Para el Canteado la Revolución era la tierra. La tierra y nada más la tierra. Tierra y Revolución unidas en un abrazo indisoluble, pero con un sentido primario del concepto. Para el Rata era

\footnotetext{
${ }^{5}$ Sefchovich dirá de Azuela: "no entiende que se asesine a una familia entera para que el padre pueda irse a la Revolución sin el remordimiento de dejarlo abandonados, ni entiende que se deje a un muerto bajo la ventana días y días a la mirada de una niña, o que se robe y se masacre a los pasajeros de un tren como hacían los cristeros fanáticos. No sabe por qué lucha Demetrio Macías" (1987, p. 89).
} 
algo más hondo y de horizontes menos limitados. Para él, era la necesidad de una subversión violenta de todos los valores existentes como única forma de dar paso a lo que México reclamaba. (1979, p. 204).

La concepción de Mancisidor sobre el campesino y sus aspiraciones de pequeño propietario se adecuaba aún más a la visión marxista, la cual considera que éstos son "pequeños burgueses" y sus intereses, conciencia y aspiraciones se limitaban a ascender dentro del orden burgués en lugar de transformarlo radicalmente, tarea ésta que se asigna únicamente a los obreros despojados de toda propiedad. Esto se ejemplifica de forma concisa en la acusación que el Rata hace a León Cardel en medio de un debate sobre el sentido de la Revolución: “-iSi tendrás metida en tu corazón de campesino la biliosa alma de un burgués...!"(1979, p. 206). La contraposición del pequeño campesino con las aspiraciones más hondas y amplias de los trabajadores asalariados es tema común en la literatura del realismo socialista, pero principalmente base de la teoría marxista y es expuesta desde el Manifiesto del Partido Comunista, en La lucha de clases en Francia 1848-1850, La Guerra civil en Francia.

\section{b) León Cardel o la conciencia}

Para profundizar más en la concepción marxista de Mancisidor basta pensar que León Cardel fue pensado como contraparte del Luis Cervantes de Azuela, personaje de clase media, culto y con estudios de medicina, que estando en posibilidades de comprender la trama de la sangrienta guerra que implicó la Revolución, termina por obtener favores políticos y económicos del movimiento revolucionario. León Cardel es, en cambio, la representación de lo que Gramcsi denominó el intelectual orgánico: hombre letrado que comprende la trama oculta detrás del aparente caos y que puede guiar y aclarar el camino para la clase social ascendente que se encuentra en lucha política. A diferencia del Curro de Azuela, Cardel no es un hombre formado en las instituciones educativas del Estado, pero esto no le restará claridad ni capacidades, antes bien sus ideas se mostrarán como las 
más avanzadas, lo que llevará al Canteado a referirse a él como Licenciado, dirá Mancisidor: "él no es capaz de concebir que un hombre como León Cardel no sea Licenciado." (1979, p. 159).

León Cardel es la conciencia más clara de los derroteros que ha de seguir la Revolución, de que la lucha de los campesinos y obreros, aún la figura del Rata, que critica y se opone a $\mathrm{El}$ Canteado, es sometida a la evaluación de León Cardel: “León Cardel estimaba al Rata. Reconocía lo vigoroso de sus razonamientos y hacía ver al Canteado cómo era preciso estar alertas para localizar al enemigo hasta entre nuestras propias filas..." (1979, p. 208). Su aparición en la novela es constante y temprana, cuando aún Mancisidor no participa, habla de él como un hombre prófugo vinculado a labores clandestinas previas al estallido de la Revolución. En los momentos más radicales y caóticos del conflicto se acomoda como dirigente y organizador, pero cuando la hegemonía se reconstituye alrededor del constitucionalismo, nuevamente entra en conflicto con el gobierno, pues para él no basta con la promulgación de la constitución de 1917, por tanto, continúa organizando y agitando a obreros y campesinos, lo que le llevará a ser aprehendido. Pero aún como huésped de la represión, Mancisidor no deja de presentarlo como el más claro de los participantes en el conflicto:

-Hay hombres tan idiotas que creen que el pensamiento puede ser encerrado dentro de las cuatro paredes de una cárcel, como si el canto de los pájaros no saliera más allá de los barrotes de su jaula...- Mientras la agitación crecía. Y obreros y campesinos pedían sus tierras y la aplicación de la legislación del trabajo. Esto era su más concreta esperanza. (1979, pp. 269-270).

Mancisidor atribuye a León Cardel las posiciones políticas más avanzadas que, en su concepción, no podían ser otras que las del pensamiento socialista. No es claro si es un socialismo de corte anarquista o comunista, históricamente habría elementos para afirmar que el personaje tendría concepciones anarquistas debido a que estaban más difundidas que las del socialismo marxista o comunismo. En todo caso León Cardel se aproxima al personaje Fedor de Demitry Furmanov (1936) a quien se le asigna la tarea de llevar la conciencia al caudillo militar Chapaiev y ayudarlo a 
comprender las causas más profundas de la revolución. Esto no sería raro considerando la circulación de novelas soviéticas en los 20’s y 30's en México, que incluían además de la obra de Gorki, La derrota de A. Fadéiev; Guerrilleros de V. Ivanov, Caballería roja de I Babel.; Cemento de F. Gladkov y La rebelión de Chapaiev. (Kuteischikova, 1981, p. 87-103).

\section{c) Efrén o la clase obrera}

Para la concepción marxista de la historia, el sujeto revolucionario por excelencia es la clase obrera, los trabajadores en las filas de la gran industria. Tal actor colectivo no se escapa a la visión de Mancisidor, antes bien es el que más está representado. Este autor, según cuenta en la novela, era hijo de una familia obrera y su padre fue quien lo llevó a enfrentar a temprana edad las problemáticas de los obreros. Dice de su padre:

Un movimiento huelguístico lo alejó de su nuevo puesto. A su lado, sin comprender lo que explicaba, le oí hablar de derechos, de deberes, de obreros y patrones y de cien cosas más que no podría recordar. Una noche participó a mi madre: -La huelga se ha ganado-. Sin embargo, él no volvió al trabajo" (1979, p. 15).

Pero además, él mismo, luego de haber pasado algunos años en la vagancia $(1979$, p. 10), buscará sumarse a las filas de los asalariados ingresando a la escuela militar de maestranza en San Juan de Ulúa como alumno de maquinista naval.

Será en la escuela de maquinaria donde conozca a otros de los personajes que retrata en su novela: El chino, Efrén y el Negro, son la representación de las aspiraciones de los trabajadores pues, aunque estudiaban en la escuela militar, sus anhelos son usar sus conocimientos en mecánica para trabajar de obreros calificados. Este grupo de amigos, aunque se separa, no dejará de ser la expresión de los obreros que participan de la Revolución. El Chino y Mancisidor andarán juntos hasta la muerte del primero, y el segundo encontrará a Efrén en la capital. No obstante, de entre los miembros de éste grupo, es Efrén quien mejor encarnará la situación de los obreros durante la 
Revolución, pues mientras los otros amigos habían pasado a ser soldados que peleaban en un ejército de campesinos, Efrén:

Vive en la capital con los suyos. Sigue siendo un obrero mecánico. Viste un traje limpio pero raído por el uso. Su rostro conserva su sello burlón, pero se ha hecho un poco adusto. Sus manos han encallecido por el trabajo y aprieta la mía con vigorosa intensidad. (1979, p. 175).

En la conversación que Mancisidor sostiene con Efrén se puede ver que el segundo es la voz de los miles de obreros, pues le pregunta: “-¿ipiensas actuar ahora? -", expresión con que Mancisidor se pregunta a su interlocutor para que éste responda por todos los que son como él. La respuesta es:

-Sí, porque lo estimamos necesario. Intervendremos nosotros: millares y millares de hombres regados por el suelo de México. [...] Somos el porvenir de la humanidad, en última instancia. $Y$ todo lo que en el mundo existe ha sido creado con nuestro esfuerzo. (1979, p. 176).

Efrén habla a nombre de la colectividad a la que pertenece: la clase obrera, sujeto revolucionario por excelencia para Mancisidor. La participación de los obreros en la Revolución, que tiene como principal acontecimiento la creación de los "batallones rojos", es narrada por él mismo poniendo el anuncio en su representante de la clase obrera: "Efrén me escribe una última carta y me participa Hemos formado los batallones rojos-. Y asegura que al fin se sabrá por qué se lucha." (1979, p. 184).

Mancisidor no quedará distante de éste fenómeno, participará de los batallones rojos y con orgullo narrará:

Me incorporo ahora a uno de los batallones rojos, integrados por obreros de las fábricas textiles, que apenas se inician en las batallas, en él se encuentra el negro, a quien se comisiona en mi compañía con lo que mi confianza crece. Los obreros me reciben con júbilo. (1979, p. 211). 
Pero Efrén sigue siendo la voz de los obreros que, luego de ser desmovilizados militarmente, exigirán aumento de salarios y el cumplimiento de la ley laboral, actos ante los cuales el gobierno responderá ilegalizando las huelgas y reprimiéndolos. Ante esta situación, Efrén será quien le haga saber a Mancisidor que se ha traicionado a la clase obrera.

\section{d) La unidad obrero-campesina}

Si bien, la Revolución mexicana no fue de corte socialista, y Mancisidor lo veía bien, no excluye que su concepción política le hiciera ver en la participación de las tropas de él y el Canteado en los Batallones rojos, la unidad entre el obrero y el campesino contra la explotación. Esta idea propia del marxismo de corte soviético, era considerada como necesaria para que ambos puedan hacer frente a la explotación y ver cumplidas sus demandas; por esto no es raro que el novelista narrara con satisfacción su incorporación a los Batallones rojos. En la visión del autor, el pacto entre la Casa del Obrero Mundial y las fuerzas constitucionalistas al mando de Carranza, no fue un error, aunque implicó la utilización de los obreros para combatir las fuerzas de los ejércitos populares de Villa y Zapata, esto dado que la tarea principal era la confrontación y liberación de México del influjo de Estados Unidos (Mancisidor, 1940, pp. 301-310; 1977, pp. 281-282). Por esto mismo, para él la revolución triunfa cuando se consolida el gobierno de Venustiano Carranza, gobierno que Mancisidor consideraba debía ser fortalecido y apoyado en su política de confrontación a la intervención de Estados Unidos (Mancisidor, 1940, pp. 310-316; 1977, pp. 261-276).

Por estos motivos, Mancisidor ve en el pacto firmado por la Casa del Obrero Mundial, la alianza de los intereses de los obreros y campesinos. En su novela esto se representa cuando el Canteado como encarnación de los campesinos, terminan por coincidir con los obreros: "ahora parecía comprender también el pensamiento de los obreros como un pensamiento propio" (1979: 212) y a la larga: "El Canteado y el Rata ya no discuten. Ante la resistencia enemiga son solamente dos voluntades unidas por el inquebrantable pensamiento de vencer. Vencer es la tierra y también la libertad." (1979, p. 242). 
Además, esta unión es consagrada por León Cardel, quien como expresión de la conciencia política del proceso Revolucionario, menciona: "Llevamos una ventaja. La de saber que tenemos al fin una bandera y un mismo espíritu de lucha. Así que los campesinos y los obreros que lo comprendan correrán a nuestro lado. Sólo entre nosotros tendrán eco sus afanes."(1979, p. 182). Y en el mismo sentido: “Como León Cardel lo previera los campesinos acuden a nuestro llamado. En sus rojas banderas llevan inscritas las palabras: "Tierra y Libertad". Y los obreros en sus estandartes negros, han grabado una blanca calavera." (1979, p. 184).

La alianza entre obreros y campesinos fracasó -Mancisidor lo reconocerá mejor en su novela que en sus textos historiográficos-, pues los obreros organizados en los batallones rojos empezaron a movilizarse política y militarmente a favor del gobierno y en contra de los campesinos. De igual manera, fracasará el pacto entre los obreros y el gobierno, pues este defendió los intereses económicos de los empresarios y se opuso a la exigencia obrera de mejoras salariales; esta nueva pugna llevó al gobierno a desarmar y desmovilizar los batallones obreros.

Así pues, Mancisidor retrata que el gobierno surgido de la Revolución, artífice de un pacto entre la clase trabajadora y la de propietarios, mandó a reprimir a los obreros al igual que a las fuerzas campesinas de Villa y Zapata. Para retratar la represión contra la clase obrera, hace aparecer a Efrén ahora como un obrero que protesta, y ocupa el papel de un militar que debe dispararle:

La multitud se aproximaba rugiente. Cabezas y brazos movían con precipitación. Al frente iba un rostro conocido. Al fijar sus ojos en mí la boca de aquel rostro me gritó algo que no escuché. Luego el hombre se golpeó el pecho con el puño cerrado como un mono enfurecido y gesticuló con visajes violentos y muy poco humanos. [...] Cuando lo tuve a unos cuantos pasos reconocí a Efrén. Sus palabras estaban llenas de odio, sus ademanes de furor.

- ¿Por qué no disparas?- me gritó descompuesto -¿Por qué? ¿Traidor!. (1979, p. 280). 
El resto de este episodio ya se ha referido antes, Mancisidor es enviado a reprimir las protestas obreras y al negarse a disparar contra los manifestantes es expulsado del ejército. Para la concepción marxista Mancisidor el disparar contra otros sujetos de su clase social implicaría un grave error derivado de la falta de conciencia de clase. Pero aún con este pasaje, y habiendo soldados que si dispararon contra los obreros, para Mancisidor la visión general de la Revolución es favorable, pues la tierra es entregada a los campesinos y los obreros movilizados políticamente harán que sus demandas se cumplan.

\section{Conclusión}

En la rosa de los vientos puede ser considerada una novela de la Revolución mexicana al igual que una obra perteneciente al realismo socialista. La trama general, los personajes y el objetivo con que fue escrita responden a la concepción marxista de la historia, lo que le confiere de un carácter excepcional que no poseen otras novelas de la Revolución mexicana, y le permite dotar de sentido a los acontecimientos que para otros novelistas son inaceptables o inconcebibles como parte de un proceso de transformación social, por ejemplo, la muerte en masa, las disputas políticas.

La visión marxista de Mancisidor opera desde el momento en que concibe responder a Mariano Azuela, y piensa en retratar a personajes conscientes del significado del proceso revolucionario que se suman a la lucha por ideales colectivos y no por intereses individuales. Estos personajes son lo que pueden enfrentar las desavenencias, peligros y complicaciones derivados de la actuación por la transformación social, transformación que a momentos parece ser desplazada por la mezquindad de intereses individuales y diluirse en la confusión. El más ejemplar de estos personajes es León Cardel, quien se presenta dotado de claridad en los momentos más confusos y que no pierde de vista las metas colectivas ni en los momentos más oscuros, es el ejemplo de que para Mancisidor estos personajes existen y son imprescindibles. 
Con En la rosa de los vientos Mancisidor cumple su objetivo, decir que la Revolución fue más que muerte o caos, además establece un deslinde entre la pureza revolucionaria y el bandidaje ${ }^{6}$ (Matute, 2011, p. 127) al exponer que si bien en la Revolución participó gente como Demetrio Macías, carentes de conciencia, en todo caso contribuyeron para que el resultado final fuera una Revolución favorable para los trabajadores del campo y la ciudad que contaban con personajes como León Cardel.

En la rosa de los vientos se expresa que, al igual que los miembros del Partido Comunista de México en las décadas de 1930 y 1940, para Mancisidor la Revolución mexicana debía ser defendida de la reacción y el imperialismo norteamericano, y más aún, debía tener continuidad en la política y en su correlato narrativo, se debía encarar la visión pesimista de Azuela y continuar la producción literaria: "iQue va a estar agotada la Revolución mexicana como fuente de creación artística! Allí están las luchas por la nacionalización petrolera; por la industrialización del país; ipor llevar el alfabeto a los pueblos más apartados del territorio nacional!" (1980a, p. 903).

Pero la visión marxista no está sólo presente en la esencia de su novela, pues algunos elementos de forma responden también a una concepción marxista de la literatura: el realismo socialista. Tal hecho es lo que hace que León Cardel a lo largo de la novela sea quien exponga con claridad las complicaciones a que se enfrentan los revolucionarios e indique a los otros personajes, y a los lectores, que el camino a seguir. La estructura de las novelas del realismo socialista de corte soviético, que influyeron en Mancisidor, tiende siempre a señalar los pasos a seguir en la lucha de las clases oprimidas y explotadas, señalar meta de la emancipación y el fin de la explotación, y esto es lo que hace León Cardel al afirmar:

Cuando los pueblos se levantan es difícil aplacarlos. El nuestro no abandonará las armas hasta que no obtenga lo que reclama. Triunfante sobre el actual enemigo seguirá peleando ¿Contra qué o contra quién? Contra todo lo que se oponga a sus designios y contra todo aquél que piense empresa fácil detener una corriente desbordada.(1979, p. 159).

\footnotetext{
${ }^{6}$ La cuestión de éste deslinde Matute la usa al analizar la obra literaria de Teja Zabre, pero considero de utilidad la idea para aplicarla a la obra de Mancisidor.
} 


\section{Referencias}

Aub, M. (1985). Guía de narradores de la Revolución Mexicana, México: Fondo de Cultura Económica.

Castro, A. (1965). La novela de la revolución, México: Aguilar.

Dessau, A. (1996). La novela de la Revolución Mexicana, México: Fondo de Cultura Económica.

Furmanov, D. (1936). Chapaief. El guerrillero rojo, Buenos Aires: Cronos.

Gurrí, J. y León, M. (1978). La investigación histórica. En consejo Técnico de Humanidades (Ed.), Las humanidades en México 1950-1975. pp. 9-92. México: Universidad Nacional Autónoma de México.

Gutierrez, J. (1983). La Obra Narrativa de José Mancisidor, tesis de licenciatura Lengua y Literaturas Hispánicas, México: Universidad Nacional Autónoma de México.

Hernández, J. (1960). Novelistas y cuentistas de la Revolución Mexicana, México: Unidad Mexicana de Escritores.

Higashi A. y Torres D. (2010). Más allá del canon de la novela de la Revolución. En Leyva, G. et al. Independencia y Revolución. Pasado, presente y futuro. pp. 384-410. México: Fondo de Cultura Económica-Universidad Autónoma Metropolitana.

Kuteischikova, V. (1981). La novela de la revolución mexicana y la primera narrativa soviética" en Aurora Ocampo (compiladora), La crítica de la novela mexicana contemporánea. México: Universidad Nacional Autónoma de México- Instituto de Investigaciones Filológicas.

León, S. (1965). Las novelas de José Mancisidor, tesis de maestría en Letras. México: Universidad Nacional Autónoma de México.

Lifshitz, M. (1985), Literatura y marxismo. Una controversia. México: Siglo XXI.

Mancisidor, J. (1940), "Síntesis histórica del movimiento social en México", en Max Beer, Historia general del socialismo y las luchas sociales. pp. 267-357. México: Márquez Editor.

Mancisidor, J. (1977), Historia de la Revolución mexicana, México: Editores Mexicanos Unidos. Mancisidor, J. (1979). En la rosa de los vientos, Obras completas III. pp. 8-283. Xalapa: Gobierno del Estado de Veracruz. 
Mancisidor, J. (1980a). Sobre literatura y filosofía. Obras completas V. Xalapa: Gobierno del Estado de Veracruz. pp. 787-931.

Mancisidor, J. (1980b). Mi deuda con Azuela, Obras completas V. pp.769-776. Xalapa: Gobierno del Estado de Veracruz

Martínez, J. (1949). Literatura mexicana del siglo XX. 1910-1949. México: Antigua Librería Robledo. Martínez, J y Domínguez, C. (1996). Literatura mexicana del siglo XX. México: Consejo Nacional para la Cultura y las Artes.

Matute, A. (2005). Aproximaciones a la historiografía de la Revolución mexicana. México: UNAM. Matute, A. (2011). La novela como acto expiatorio. Teja Zabre y la Revolución. En Lorente, A. Navascués, J. Narrativa de la Revolución mexicana: Realidad histórica y ficción. pp. 121-132. Madrid: Verbum.

Monsiváis, C. (2019, 19 de junio). Ruta (1938-1939) El breve reinado de la izquierda cultural en México". América: Cahiers du CRICCAL. Recuperado de https://www.persee.fr/issue/ameri 0982-9237 1990 num 4 1?sectionld=ameri 0982$\underline{92371990 \text { num } 41978}$

Negrín, E. (1994). La ciudad roja de José Mancisidor: Una novela proletaria mexicana en Juan Villegas (coord.), Actas del XI Congreso de la AlH. Lecturas y relecturas de textos españoles, latinoamericanos y US latinos (314-322). s/l.: Asociación Internacional de HispanistasUniversity of California. Vol. 5. Recuperado de https://cvc.cervantes.es/literatura/aih/pdf/11/aih_11 5 037.pdf

Ruffinelli, J. (1982). Literatura e ideología: el primer Azuela. México: Premia.

Ruiz, A. (2010), Trasgresión y cultura popular en el relato de la Revolución. En Gustavo Leyva, G. et al. Independencia y Revolución. Pasado, presente y futuro. pp. 369-383. México: Fondo de Cultura Económica-Universidad Autónoma Metropolitana.

Sánchez, A. (1994). Tres socialistas frente a la revolución mexicana: José Mancisidor, Rafael Ramos Pedrueza, Alfonso Teja Zabre. México: CONACULTA. 
Sefchovich, S. (1987). México: País de ideas, país de novelas. Una sociología de la literatura mexicana. México: Grijalbo.

Zhdanov, A. (1968). El frente ideológico y la literatura. Gorki y Zhdanov, Literatura, filosofía y marxismo. pp. 61-100. México: Grijalbo. .

Zhdanov. A. (2019, junio, 20). Discurso en el primer congreso de escritores soviéticos. El Machete. Revista teórica y política del PCM. Recuperado de http://elmachete.mx/index.php/2018/04/16/discurso-en-el-primer-congreso-de-escritoressovieticos-1934/

Torres, D. (2015). Avatares editoriales de un "género": tres décadas de la novela de la Revolución mexicana. México: Bonilla Artiga Editores-ITAM. 